\title{
Design of a spline horn for a W-band gyro-TWA
}

\author{
Liang Zhang, Wenlong He, Craig R. Donaldson, and \\ Adrian W. Cross \\ Department of Physics, SUPA, \\ University of Strathclyde \\ Glasgow, UK
}

\author{
Duncan Robertson, Robert Hunter, Graham Smith \\ SUPA, School of Physics and Astronomy, \\ University of St. Andrews, \\ St. Andrews, UK
}

\begin{abstract}
A spline horn for use in a W-band gyro-TWA was design and manufactured. The horn was designed to have a high Gaussian content over the whole operating frequency band of 90 $-100 \mathrm{GHz}$. It also had a low reflection of the TE11 mode and high directivity.
\end{abstract}

Keywords—horn, Gaussian content, gyro-TWA.

\section{INTRODUCTION}

W-band Gyrotron backward wave oscillators (gyro-BWO) and gyrotron travelling wave amplifiers (gyro-TWA) are currently been studied in the Unveristy of Strathclyde. They are promissing high power microwave sources that can be potentially used in many applications such as plasma heating, radio detection and ranging (RADAR), and spectroscopes. A gyro-BWO [1] using helically corrugated interaction region achieved a maximum output power of $12 \mathrm{~kW}$ in the frequency range of $88-102.5 \mathrm{GHz}$ by adjusting the cavity magnetic field The electron beam used in the experiment was $40 \mathrm{kV}$ and 1.5 A with large orbit axial encycling. The gyro-TWA is based on the similar experimental setup but with a side-wall input coupler [2 - 4]. It was designed to generate an output power of $5 \mathrm{~kW}$ in the operating frewuency range of $90-100 \mathrm{GHz}$.

For some applications, it is preferred to have the Gaussian beam, such as RADAR and Electron paramagnetic resonance (EPR). However, for the helically corrugated waveguide [5] used in the gyro-TWA and gyro-BWO, the output mode of the microwave radiation is the $\mathrm{TE}_{11}$ mode. A mode converter will be required. Different type of mode converters have been developed in the literature. The Vlasov launchers have been widely used in gyrotrons, however their bandwidths are quite narrow, and not suitable for the gyro-TWA. The corrugated horn [6] has good performance such as broad bandwidth and high directivity. Two corrugated horns had been designed and measured in the past for the gyro-TWA. The first one achieved an $-30 \mathrm{~dB}$ reflection and a Gaussian percentage of $98 \%$ over the frequency range of $90-100 \mathrm{GHz}$. Further improvement was made to achieve a Gaussian percentage of $99.4 \%$ at 94 $\mathrm{GHz}$. However the corrugated horn still has the disadvantage of complicated machining processes as well as high cost. In the experiment, the corrugated horn was assembled before a 3layer microwave window $[7,8]$, it was found that the corrugation sections were not ideally for the ultra-high vacuum environment.

In this paper, a smooth spline profile horn [9, 10] is investigated, in the aim to find an alternative solution to the corrugated horn which is low cost and ultra-high vacuum friendly. The design targets are the same as the previous corrugated horn, i.e., low $\mathrm{TE}_{11}$ reflection, high Gaussian percentage and high directivity.

\section{SimULATIONS}

For a smooth horn with arbitrary profile, it could be approximated as a series of circular waveguide steps, as shown in Fig. 1, the microwave properties of which can be efficiently simulated by using the mode matching method. The simulation results would be accurate if the discrete section length $L$ is small enough. However, that would increase the simulation time. A balance of the simulation accuracy and the simulation time could be decided by a parameter sweep with different values of $L$.

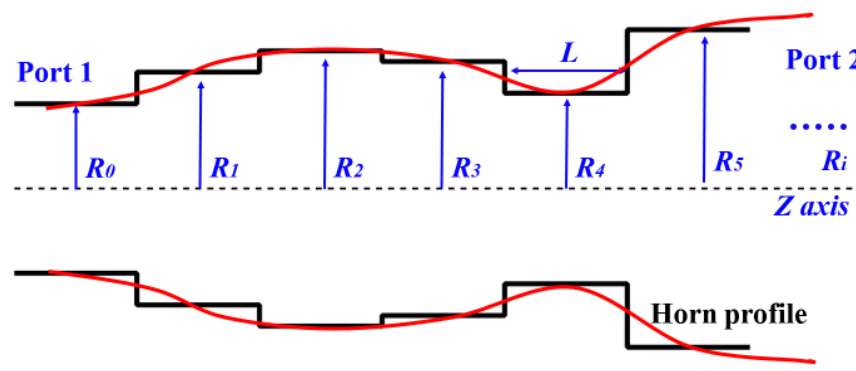

Fig.1. Approximation of a spline profile horn.

The waveguide steps would allow mode conversions between the $\mathrm{TE}_{1 \mathrm{n}}$ and $\mathrm{TM}_{1 \mathrm{n}}$ modes, hence generate a hybrid mode content at the output aperture of the horn. If the mode percentages are in proper values, a quasi-Gaussian modes could be formed. For example, a $\mathrm{HE}_{11}$ mode composed by $85 \%$ $\mathrm{TE}_{11}$ mode and $15 \% \mathrm{TM}_{11}$ mode with 180 degree phase difference has a $98 \%$ Gaussian content compared with a fundamental Gaussian mode which has a beam waist ratio of 0.64 . From the mode matching method, the transmission and reflection of the spline horn could be obtained from the scattering matrix. Therefore the electric field at the output aperture could be obtained, and could be expressed as the sum of the TE and TM modes. 
The coupling coefficient of the apeture field and the fundermental Gaussian mode could be calculted by the convolution of the two fields. The far field pattern of the horn can be evaluated from the apeture field method, given by [11].

\section{OPTIMIZATIONS AND CONSTRUCTION}

The profile of the spline horn was optimized by using a multiple-objective optimization method [12]. Two goal functions were used in the optimization. One was to minimize the $\mathrm{TE}_{11}$ reflection, and the other to maximize the average Gaussian percentage over the operating frequency range. The optimized profile achieved a maximum Gaussian percentage of nearly $98 \%$ and a beam waist ratio in the range of 0.6 to 0.63 , as shown in Fig. 2(a). The reflection of $\mathrm{TE}_{11}$ mode was lower than $-60 \mathrm{~dB}$, and the directivity was about $26 \mathrm{~dB}$.
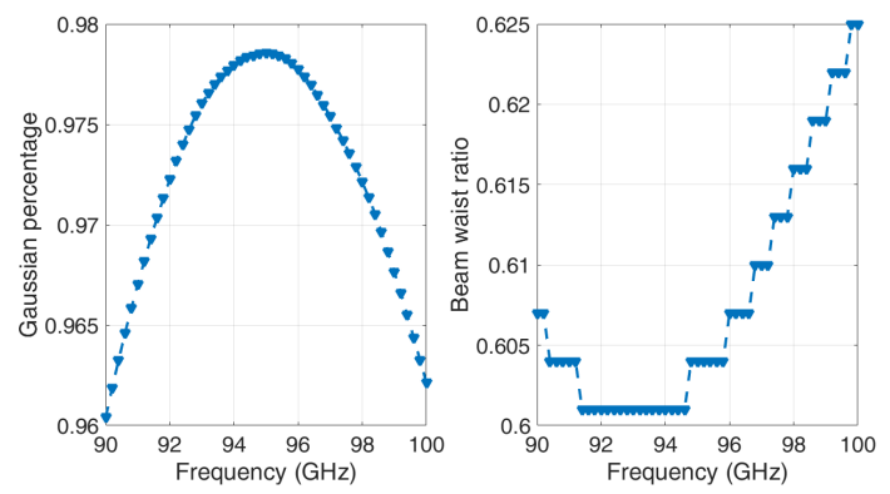

(a)

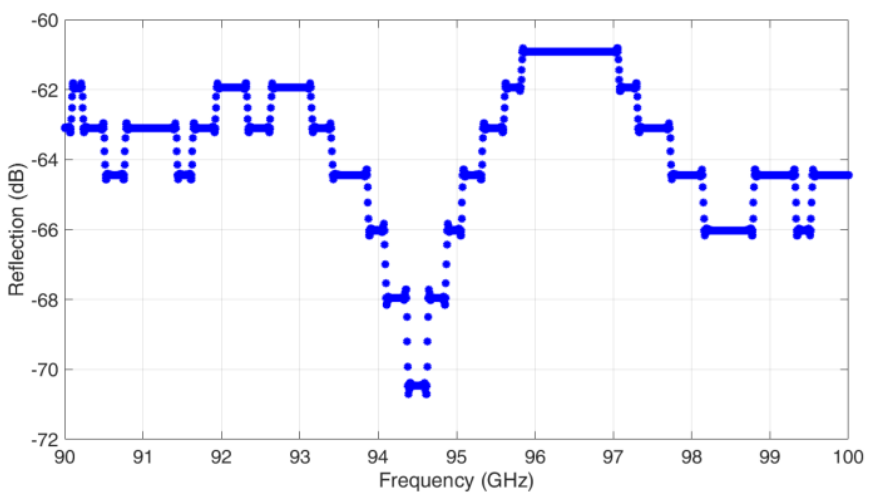

(b)

Fig.2. Simulation result of the spine profile horn.

The optimized horn had a non-linear part and a linear taper joint together. The former was directly machined by a precise computer numerical control (CNC) machine on a copper rod, as shown in Fig. 3. The non-linear part and the smooth linear taper will be brazed together. Its performance, including the reflection, far field pattern as well as the field distribution at the aperture and hence the Gaussian percentage will be measured after the assembly.

\section{ACKNOWLEDGMENT}

This work was supported by the Engineering and Physical Sciences Research Council (EPSRC) U.K. under Research
Grant EP/K029746/1, and Science and Technology Facilities Council (STFC) U.K. under Research Grants ST/K006673/1 \& ST/K006703/1, ST/N002326/1 \& ST/N002318/1.

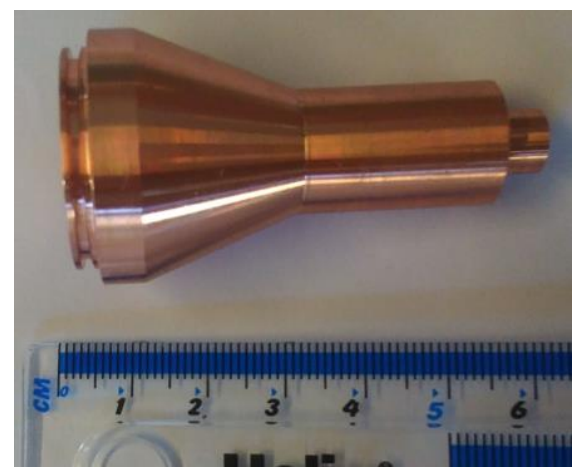

Fig.3. machined profile horn without been brazed with vacuum flanges.

\section{REFERENCES}

[1] W. He, C. R. Donaldson, L. Zhang, K. Ronald, P. McElhinney, and A.W Cross, "High power wideband gyrotron backward wave oscillator operating towards the terahertz region," Phys. Rev. Lett., vol. 110, no. 16, p. $165101,2013$.

[2] L. Zhang, W. He, C. R. Donaldson, J. R. Garner, P. McElhinney, and A. W. Cross, "Design and measurement of a broadband sidewall coupler for a W-band gyro-TWA," IEEE Trans. Microw. Theory Techn., vol. 63, no. 10, pp. 3183-3190, Oct. 2015.

[3] J. R. Garner, L. Zhang, C. R. Donaldson, A. W. Cross, and W. He, "Design Study of a Fundamental Mode Input Coupler for a $372-\mathrm{GHz}$ Gyro-TWA I: Rectangular-to-Circular Coupling Methods," IEEE Trans. Electron Devices, vol. 63, no. 1, pp. 497-503, Jan. 2016.

[4] J. R. Garner, L. Zhang, C. R. Donaldson, A. W. Cross, and W. He, "Design Study of a $372 \mathrm{GHz}$ Higher Order Mode Input Coupler", IEEE Trans. Electron Devices, vol. 63, no. 8, pp. 3284-3290, Aug. 2016.

[5] L. Zhang, S. V. Mishakin, W. He, S. V. Samsonov, M. McStravick, G. G. Denisov, A. W. Cross, V. L. Bratman, C. G. Whyte, C. W. Robertson, A. R. Young, K. Ronald, A. D. R. Phelps, "Experimental study of microwave pulse compression using a five-fold helically corrugated waveguide", IEEE Trans. Microw. Theory Tech., vol. 63, no. 1, pp. 1090-1096, Jan. 2015.

[6] P. McElhinney, C. R. Donaldson, L. Zhang, and W. He, "A high directivity broadband corrugated horn for W-band gyro-devices," IEEE Trans. Antennas Propag., vol. 61, no. 3, pp. 1453-1456, March 2013.

[7] C. R. Donaldson, W. He, L. Zhang, and A. W. Cross, "A W-band multilayer microwave window for pulsed operation of gyro-devices," IEEE Microw. Wireless Compon. Lett., vol. 23, no. 5, pp. 237-239, May 2013.

[8] C. R. Donaldson, P. McElhinney, L. Zhang, and W. He, "Wide-band $\mathrm{HE}_{11}$ mode terahertz wave windows for gyro-amplifiers," IEEE Trans. THz Sci. Technol., vol. 6, no. 1, pp. 108-112, Jan. 2016.

[9] C. Granet, T. S. Bird, and G. L. James, "Compact multimode horn with low sidelobes for global earth coverage," IEEE Trans. Antennas Propagat., vol. 48, pp. 1125-1133, July 2000.

[10] C. Granet, G. L. James, R. Bolton and G. Moorey, "A smooth-walled spline-profile horn as an alternative to the corrugated horn for wide band millimeter-wave applications," IEEE Transactions on Antennas and Propagation, vol. 52, no. 3, pp. 848-854, Mar. 2004.

[11] A. Ludwig, "Radiation pattern synthesis for circular aperture horn antennas," IEEE Trans. Antennas Propag., vol. 14, no. 4, pp. 434-440, Jul. 1966.

[12] L. Zhang, W. He, C. R. Donaldson, A. W. Cross, "Bandwidth Study of the Microwave Reflectors with Rectangular Corrugations," J. Infrared Milli. Terahz Waves, pp.1-11, 2016. 